to $50 \mathrm{ml}$ are acceptable; the choice depends largely on the size of the patient. From the points of view of safety and efficiency, the optimal syringe size is one that can accommodate a cycle volume that yields an $F$ value nearest 0.05 (i.e., $5 \%$ of estimated total blood volume). In older patients the $F$ values are of necessity in the range of 0.02 to 0.01 , because of the limitation imposed by a maximum syringe volume that is small in relation to patient blood volume. As a result, the number of cycles ( $n$ ) may become unacceptably large. Should this become a practical limitation, the technique of exchange may be changed to one using simultaneous infusion and withdrawal with standard plastic blood bags connected to separate intravenous sites.

Additional considerations when employing the method presented include estimation of total blood volume of the patient. In the normal newborn infant this is considered to be in the range of 85 to $100 \mathrm{ml} / \mathrm{kg}$, depending upon gestational age. Among older infants and children, normal blood volume was considered to be $75 \mathrm{ml} / \mathrm{kg}$. Patients with polcythemia secondary to cyanotic congenital heart disease may have blood volumes in excess of 100 $\mathrm{ml} / \mathrm{kg}{ }^{.}$

The hematocrit value of donor packed red blood cells varied substantially in our series; it is recommended, therefore, that this be measured prior to final calculation of the required volume of donor blood.

Review of patient data presented in two reports ${ }^{5 .}$ ' of severely anemic children suggests good agreement with data predicted by our formula. Further experience by others is encouraged to validate the results reported here.

We thank Drs. David Rubinstein, Eileen Tyrala, and Jeanne Manser of the Intensive Care Nurseries of St. Christopher's Hospital for Children and Temple University Hospital for allowing us to study the infants under their care.

\section{REFERENCES}

1. Ward T: Exchange transfusion in severe anemia, $\mathrm{Br}$ Med $\mathrm{J}$ 1:631, 1952.

2. Fullerton WT, and Turner AG: Exchange transfusion in the treatment of severe anemia of pregnancy, Lancet 1:75, 1962.

3. Cutting HO, and Marlow AA: Partial exchange transfusion in severe chronic anemia, Arch Intern Med 117:478, 1966.

4. Editorial, Lancet 2:270, 1966.

5. Purugannan HB, and Naiman JL: Exchange transfusion in severe iron deficiency anemia prior to emergency surgery, J Pediatr 69:804, 1966.

6. Stubbs PA, and Avery GB: Partial exchange transfusion-a treatment procedure for severe non-hemolytic anemia in newborns, Clin Pediatr 6:301, 1967.

7. Nieburg PI, and Stockman JA: Rapid correction of anemia with partial exchange transfusion, Am J Dis Child 131:60, 1977.

8. Naiman JL: Polycythemia, in Gellis SS, and Kagan BM: Current pediatric therapy, Vol 6, Philadelphia, 1973, WB Saunders Company, pp 268-9.

9. Rosenthal A, Nathan DG, Marty AT, Button LN, Miettinen OS, and Nadas AS: Acute hemodynamic effects of red cell volume reduction in polycythemia of cyanotic congenital heart disease, Circulation 42:297, 1970.

\title{
Lethal hypoglycemia in a child with a deficiency of 3-hydroxy-3-methylglutarylcoenzyme A lyase
}

\author{
Ruud B. H. Schutgens, Ph.D., Hugo Heymans, M.D., Arnold Ketel, M.D., Hein A. Veder, \\ Amsterdam, The Netherlands, Marinus Duran, Ph.D., Dirk Ketting, and Sybe K. Wadman, Ph.D., \\ Utrecht, The Netherlands
}

ThE CLINICAL AND BIOCHEMICAL ASPECTS of three inborn errors of leucine metabolism-maple syrup urine disease, isovaleric acidemia, and 3-methylcrotonylglycinuria--have been well defined. The clinical pattern

From the Paediatric Clinic Academic Hospital of the University of Amsterdam and University Children's Hospital "Het Wilhelmina Kinderziekenhuis."

Reprint address: Paediatric Clinic Academic Hospital of the University of Amsterdam, Binnengasthuis, Grimburgwal 10, Amsterdam, The Netherlands. includes intermittent metabolic acidosis and ketosis, feeding difficulties, and neurologic abnormalities of varying degree.' Recently a fourth defect of leucine metabolism,

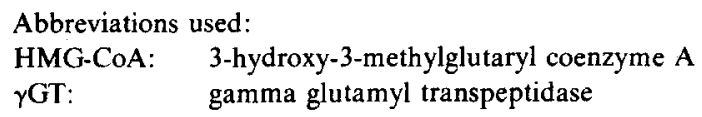

3-hydroxy-3-methylglutaryl-CoA lyase deficiency, was discovered. ${ }^{2}{ }^{3}$ In this disease hypoglycemia and a characteristic excretory pattern of organic acids, including 


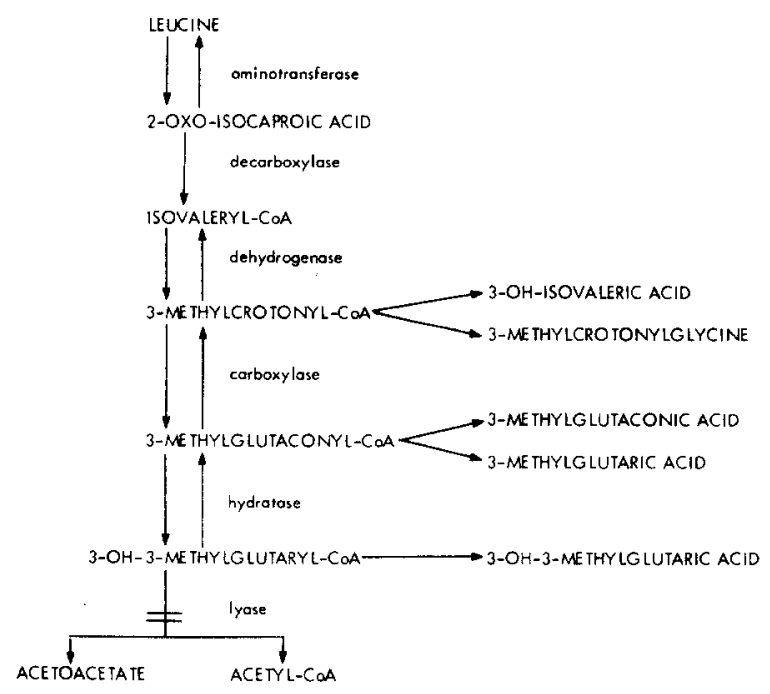

Figure. Metabolic pathway of leucine metabolism.

3-hydroxy-3-methylglutaric acid, 3-methylglutaconic acid, 3-methylglutaric acid, and 3-hydroxyisovaleric acid, are the major features. We report a second patient with this enzyme defect. This boy had only two episodes of severe hypoglycemia, but died during the second. The diagnosis was made postmortem by gas chromatography and mass spectrometry of urinary organic acids and assay of the enzyme in stored liver tissue.

\section{CASE REPORT}

The patient was born of healthy parents of Moroccan origin, after a normal pregnancy and delivery, with a birth weight of $3,750 \mathrm{gm}$. On the second day of life he was admitted to our clinic because of cyanosis and hypotonia. His weight was $3,520 \mathrm{gm}$. He had marginal cyanosis, hypotonia, dyspnea, hypothermia $\left(34.2^{\circ} \mathrm{C}\right.$ ), and hepatomegaly. On admission, the blood glucose concentration was found to be $3.6 \mathrm{mg} / \mathrm{dl}$ and he had a metabolic acidosis ( $\mathrm{pH} 7.24, \mathrm{PCO}, 35.8 \mathrm{~mm} \mathrm{Hg}$, standard bicarbonate 15.6 $\mathrm{mmol} / \mathrm{l}$ ). After correction of the hypoglycemia his condition improved rapidly, and blood glucose values remained normal. However, a compensated metabolic acidosis persisted until the ninth day of life. Blood lactate and amino acid values were normal during this time, but several liver functions were abnormal (total bilirubin $6.9 \mathrm{mg} / \mathrm{dl}$, conjugated $4.5 ; \gamma \mathrm{GT}$ up to $206 \mathrm{U} / \mathrm{l}$ measured at $25^{\circ} \mathrm{C}$; cholesterol $58 \mathrm{mg} / \mathrm{dl}$ ). All serologic and virologic tests proved to be negative and liver functions returned to normal in 3.5 months.

Gas chromatographic analysis of organic acids in the urine of the patient revealed elevated excretion of several unidentified organic acids. During the studies to characterize these acids the patient was discharged from the hospital on a protein-restricted diet. In the course of follow-up, when he was regularly seen in our outpatient clinic, he was growing in the ninetieth percentile for weight and height.

At the age of 6 months the infant was readmitted because of rapidly developing cyanosis, vomiting, and hypotonia. A few minutes after readmission he died. The blood glucose concentration was less than $1.8 \mathrm{mg} / \mathrm{dl}$; insulin was less than $1 \mathrm{mU} / 1$. A history relating that the urine had the odor of sweaty feet during the three preceding days, after a recent change in the diet was recorded. Later we calculated that the consequence of this dietary change had been an increase in leucine intake from about 1.2 to $1.5 \mathrm{~g} /$ day. Five days prior to readmission the patient received the first standard vaccinations against diphtheria, pertussis, tetanus, and polio.

\section{RESULTS OF SPECIAL LABORATORY INVESTIGATIONS}

The analysis of trimethylsilyl derivatives of acidic metabolites extracted from the urine obtained during the first observation period revealed the presence of an excessive amount of 3-hydroxy-3-methyl-glutaric acid, 3-hydroxyisovaleric acid, 3-methylglutaconic acid, and 3-methylglutaric acid. The mass spectra proved to be identical to those of the synthetic compounds. The presence of these acids is considered to be characteristic of a deficiency of HMG-CoA lyase (EC 4.1.3.4)+. 5 (Figure). The activity of this enzyme was measured subsequently in a liver needle biopsy specimen taken 15 minutes after cardiac arrest, using the radiochemical procedure of Clinkenbeard et al. ${ }^{6}$ In contrast to controls, no HMG-CoA lyase activity was detectable in the patient's liver, whereas a mitochondrial control enzyme (malate dehydrogenase) had normal activity.

\section{DISCUSSION}

The diagnosis of 3-hydroxy-3-methylglutaric aciduria was made primarily on the basis of the abnormal excretory pattern of organic acids. Rapid identification of the acids by mass spectrometry was hampered because most of the reference compounds could not be purchased. The profile of organic acids proved to be identical to that described by Faull et al." We could not detect 3-methylcrotonylglycine, a compound to be expected when 3-methylcrotonyl-CoA accumulates (Figure). However, it is questionable whether simple ethylacetate extraction and trimethylsilylation, as we used, is adequate for detection of small amounts of this compound.

An HMG-CoA lyase deficiency in liver will result in a defective intra-mitochondrial cleavage of $\mathrm{HGM}-\mathrm{CoA}$ to acetoacetic acid and acetylCoA. This reaction is essential in leucine catabolism as well as in ketone body formation (Figure).

A deficiency of HMG-CoA lyase has been found in only one other patient by Wysocki and Hähnel. ${ }^{7}$ " In their controls, HMG-CoA lyase activity was found in leukocytes and in cultured skin fibroblasts, a finding which we could confirm. Enzymatic studies in the parents of their patient indicated an autosomal recessive mode of inheri- 
tance. Enzyme determinations in the parents of our patient were not allowed.

The extreme hypoglycemia observed in our patient may be the result of several factors. This enzyme defect results in impaired ketone body formation, thereby removing the glucose sparing effect of fatty acid oxidation. Leucine does not accumulate, thus a direct lowering effect of this amino acid on blood glucose by hormonal action (insulin) is not to be expected. However, the exact mechanism of so-called leucine-induced hypoglycemia ${ }^{\theta}$ is not well understood and might represent an effect upon blood glucose, similar to that observed in 3-hydroxy-3-methylglutaric aciduria. We can imagine that a combination of both effects would lead to the extreme hypoglycemia found in our patient.

Restriction of leucine from the diet of these patients will probably prevent clinical deterioration. Early recognition of the underlying enzymatic defect is therefore essential. As the enzyme is detectable in fibroblasts, prenatal diagnosis may be possible.

We thank Prof. Dr. W. H. H. Tegelaers for his advice and critical comments; Miss W. J. M. Berntssen and R. Balkenende for their expert technical assistance; and Mrs. P. WolvetsBoomkamp and P. Kok for preparing the manuscript.

\section{REFERENCES}

1. Tanaka K: Disorders of organic acid metabolism, in Gaull GE, editor: Biology of brain dysfunction, vol 3, New York, 1975, Plenum Publishing Corp., pp 145-214.
2. Faull K, Bolton P, Halpern B, Hammond J, Danks DM, Hăhnel R, Wilkinson SP, Wysocki SJ, and Masters Pl: Patient with defect in leucine metabolism, $N$ Engl $J$ Med 294:1013, 1976.

3. Wysocki SJ, Wilkinson SP, Hähnel R, Wong CYB, and Panegyres PK: 3-Hydroxy-3-methylglutaric aciduria, combined with 3-methylglutaconic aciduria, Clin Chim Acta 73:553, 1976.

4. Faull KF, Bolton PD, Halpern B, Hammond J, and Danks DM: The urinary organic acid profile associated with 3-hydroxy-3-methylglutaric aciduria, Clin Chim Acta 73:553, 1976.

5. Wysocki SJ, and Hahhnel R: 3-Methylcrotonylglycine excretion in 3-hydroxy-3-methylglutaric aciduria, Clin Chim Acta 86:101, 1978.

6. Clinkenbeard KD, Reeds WD, Mooney RA, and Lane MD: Intracellular localisation of the 3-hydroxy-3-methylglutaryl coenzyme A cycle enzymes in liver, J Biol Chem 250:3108, 1975.

7. Wysocki SJ, and Hähnel R: 3-Hydroxy-3-methylglutaric aciduria: 3-hydroxy-3-methylglutaryl coenzyme A levels in leucocytes, Clin Chim Acta 73:373, 1976.

8. Wysocki SJ, and Hähnel R: 3-Hydroxy-3-methylglutaric aciduria: deficiency of 3-hydroxy-3-methylglutaryl coenzyme A lyase, Clin Chim Acta 73:349, 1976.

9. Cornblath $M$, and Schwartz $M$ : Leucine-induced hypoglycemia, in Disorders of carbohydrate metabolism in infancy, ed 2. Philadelphia, 1976, WB Saunders Co, pp 420-424.

\title{
Iliofemoral venous thrombosis in an infant: Diagnosis by radionuclide venography
}

\author{
Stephen R. DeLong, M.D.,* Alan E. Gober, M.D., Mariano Fernandez-Ulloa, M.D., \\ David M. Rogovitz, M.D., and Michael J. Gelfand, M.D., Cincinnati, Ohio
}

ILIOFEMORAL VENOUS THROMBOSIS and resultant pulmonary embolism commonly affect the adult population. However, this entity is uncommon in children and rare in infants. ${ }^{1.2}$ We recently studied an infant who presented to the Cincinnati Children's Hospital Medical Center with signs and symptoms of iliofemoral venous thrombosis of the right lower extremity.

\section{CASE REPORT}

A 16-day-old white male infant presented with a swollen, discolored right lower extremity discovered on the day of *Reprint address: Radioisotope Laboratory, Cincinnati General
Hospital, Cincinnati, OH 45267. admission. The infant was a $2,895 \mathrm{gm}$ term product of a 32-year-old gravida 3, para 3 mother. Pregnancy was complicated by the need for three amniocenteses for possible $\mathrm{Rh}$ isoimmunization noted after the birth of the second child. Delivery was by elective repeat cesarean section at 37 weeks' gestation. An eight-day nursery-course was complicated by hyperbilirubinemia requiring phototherapy and a transfusion of packed red blood cells at 6 days of age. At no time was umbilical arterial or venous catheterization performed, nor was femoral arterial or venous puncture done for blood sampling. Circumcision was performed at 8 days of age on the day of discharge. The infant did well except for one isolated rectal temperature of $100.7^{\circ} \mathrm{F}$ several days prior to admission.

Physical examination revealed a vigorous, well-developed 